\title{
PENGEMBANGAN MEDIA PEMBELAJARAN BERBASIS VIDEO TUTORIAL PADA MATA KULIAH MEKANIKA TANAH \\ Anwar Efendi $i^{1}$,Sri Sumarni ${ }^{2}$, Agus Efendi ${ }^{3}$ \\ Email: anwarefendi@fkip.uns.ac.id
}

\begin{abstract}
ABSTRAK
Tujuan penelitian ini adalah untuk: (1) Menghasilkan media pembelajaran berbasis video tutorial pada mata kuliah mekanika tanah. (2) Mengetahui tingkat kelayakan media pembelajaran berbasis video tutorial pada mata kuliah mekanika tanah.

Penelitian ini menggunakan metode penelitian riset dan pengembangan, dilakukan dengan pengembangan media pembelajaran berbasis video tutorial. Prosedur pengembangan media pembelajaran dilakukan melalui: (1) Tahap studi pendahuluan antara lain: studi literatur dan studi lapangan. (2) Tahap pengembangan dilakukan dengan pembuatan draft desain model / perancangan yang dibagi menjadi 3 bagian diantaranya: menyusun materi, membuat naskah dan menyiapkan storyboard, pengambilan video dan editing video. Selanjutnya validasi penilaian oleh para ahli / pakar materi, pakar media, pakar pembelajaran dan uji coba terbatas maupun uji coba luas untuk menilai kelayakan media pembelajaran yang dibuat. (3) Tahap evaluasi merupakan tahap akhir dari proses pengembangan terkait model final media pembelajaran berbasis video tutorial pada mata kuliah mekanika tanah.

Hasil penelitian menunjukkan bahwa tersusunnya media pembelajaran berbasis video tutorial pada mata kuliah mekanika tanah dengan tingkat kelayakan berdasarkan penilaian ahli materi diperoleh persentase sebesar 79,58 \% termasuk kategori layak, penilaian ahli media diperoleh persentase sebesar 77, $5 \%$ termasuk kategori layak, penilaian ahli pembelajaran dengan persentase sebesar 86, $13 \%$ termasuk kategori sangat layak. Hasil uji coba terbatas hasil yang diperoleh persentase sebesar 86,13 \% termasuk kategori sangat layak. Hasil uji coba luas diperoleh persentase sebesar 75, 867\% termasuk kategori layak.
\end{abstract}

Kata Kunci: media, pembelajaran, mekanika tanah, video, tutorial

\footnotetext{
${ }^{1}$ Mahasiswa Program Studi Pendidikan Teknik Bangunan FKIP UNS

${ }^{2}$ Staf Pengajar Program Studi Pendidikan Teknik Bangunan FKIP UNS

${ }^{3}$ Staf Pengajar Program Studi Pendidikan Teknik Bangunan FKIP UNS
} 


\title{
DEVELOPMENT OF INSTRUCTIONAL MEDIA BASED ON VIDEO TUTORIALS IN SOIL MECHANICCOURSE \\ Anwar Efendi ${ }^{1}$, Sri Sumarni ${ }^{2}$, Agus Efendi $i^{3}$ \\ Email: anwarefendi@fkip.uns.ac.id
}

\begin{abstract}
The objectives of this study are to: (1) Produce instructional media based on video tutorials in the course of soil mechanic. (2) Determine the feasibility of instructional media based on video tutorials in the course of soil mechanic.

The procedures of designing instructional media were done trough: (1) Preliminary study stage was conducted by literature study, that was by conducting field study / observation, (2) the development stage by doing the drafting of model design which was divided into three sections including: preparing the draft of learning material with the lecturer of practical course of soil mechanics, creating a script and preparing a storyboard, capturing video, editing video. Next stage was to validate the assessment to the expert of media and learning material to assess the feasibility of instructional media created. (3) The evaluation stage was the final stage of the design process related to the final model of instructional media based on video tutorials in the course of soil mechanics.

The result showed that the drafting of learning media based on video tutorials in soil mechanic course with feasibility level according to the assessment by material experts was obtained by $79,58 \%$ which was included feasible, assessment by media experts was obtained by $77,5 \%$ which was included feasible, and assessment by learning experts was obtained by 86,13 which was included very feasible. The limited trial result obtained percentage by $86,13 \%$ which was included very feasible. The result of extensive trial obtained percentage by $75,86 \%$ which was included feasible.
\end{abstract}

Keywords: learning, media, soil mechanics, video, tutorials

\footnotetext{
${ }^{1}$ Student Structural Engineering Education FKIP UNS

${ }^{2}$ Lecturer Structural Engineering Education FKIP UNS

${ }^{3}$ Lecturer Structural Engineering Education FKIP UNS
} 


\section{PENDAHULUAN}

Praktek mekanika tanah merupakan bagian dari mata kuliah mekanika tanah yang wajib ditempuh oleh mahasiswa Pendidikan Teknik Bangunan. Mata kuliah mekanika tanah bertujuan untuk menyelidiki sifat-sifat tanah, dipandang dari sudut teknik sipil yaitu terutama tanah untuk dasar bangunan dan tanah sebagai bahan bangunan. Pembelajaran yang sering dilaksanakan oleh dosen ketika praktek mekanika tanah adalah memberikan penjelasan setiap awal praktek dan mahasiswa diwajibkan mempelajari sendiri modul atau petunjuk praktek mekanika tanah. Observasi yang telah dilakukan ditemukan beberapa mahasiswa kurang faham ketika praktek, yang berakibat tidak tepat waktu saat melaksanakan praktek mekanika tanah secara langsung.

Pemanfaatan media pembelajaran berbasis video tutorial dengan software pinnacle studio belum dimanfaatkan pada mata kuliah mekanika tanah. Padahal penggunaan software pinnacle studio terdapat efek-efek visual, sehingga dapat menghasilkan video tutorial yang menarik, ditambah fasilitas dan keunggulan yang lengkap seperti fasilitas capture, editing dan burning disk HD. Maka dari itu penggunaan media pembelajaran berbasis video tutorial dengan software pinnacle studio akan lebih membantu mahasiswa dalam memahami materi yang disampaikan oleh dosen. Hal tersebut disebabkan oleh media pembelajaran dirancang lebih menarik dan mahasiswa bisa menggunakan media tersebut secara mandiri ketika diluar jam perkuliahan.

Dengan demikian, apabila multimedia pembelajaran dipilih, dikembangkan, digunakan dan dimanfaatkan secara tepat dan baik akan memberi manfaat yang sangat besar dalam proses belajar mengajar. Oleh karena itu, perlu perhatian khusus tentang multimedia pembelajaran ini agar bisa digunakan di Program Studi Pendidikan Teknik Bangunan FKIP UNS. Karena ini sangat membantu dosen dan memotivasi mahasiswa, serta meningkatkan hasil belajar dalam pembelajaran baik secara individu maupun kelompok.

Menurut Riyana (2007: 2) media video pembelajaran adalah media yang menyajikan audio dan visual yang berisi pesan-pesan pembelajaran baik yang berisi konsep, prinsip, prosedur, teori, aplikasi untuk membantu pemahaman terhadap suatu materi pembelajaran. Menurut Susilana dan Riyana (2009: 147) model tutorial adalah pembelajaran melalui komputer dimana siswa dikondisikan untuk mengikuti alur pembelajaran yang sudah terprogram dengan penyajian materi dan latihan soal. Pendapat di atas dapat disimpulkan bahwa video tutorial adalah media pembelajaran yang menyampaikan pesan kepada siswa berupa audio dan visual yang didalamnya terdapat materi pembelajaran interaktif sehingga siswa dapat belajar secara mandiri yang tidak dibatasi dengan tempat. 
Media pembelajaran merupakan hal yang terpenting untuk berlangsungnya suatu pembelajaran dikelas, pembelajaran yang kreatif, komunikatif, dan inovatif yang dapat mendukung dalam meningkatkan hasil belajar siswa, dalam hal ini kata "media" berasal dari bahasa latin dan merupakan jamak dari kata "medium", yang secara harfiah berarti "perantara atau pengantar". Media merupakan wahana penyalur informasi belajar atau penyalur pesan. (Djamrah dan Aswan, 2010: 120).

Arsyad (2007: 6) menyatakan bahwa "media pembelajaran mempunyai beberapa istilah diantaranya alat pandang dengar, bahan pengajaran (instructional material), komunikasi pandang dengar (audio visual communication), pendidikan alat peraga pandang (visual education), teknologi pendidikan (educational technology), alat peraga dan alat penjelas.

$\begin{array}{llr}\text { Dari pendapat di atas dapat } \\ \text { disimpulkan bahwa } & \text { media } \\ \text { pembelajaran } & \text { yang } & \text { inovatif }\end{array}$ merupakan alat untuk menyampaikan informasi belajar dan pesan dengan memanfaatkan kemajuan teknologi dan informasi, sehingga mahasiswa dapat memahami materi yang disampaikan oleh dosen menjadi lebih mudah. Untuk itu diperlukan media pembelajaran yang baik dan sesuai pada praktek mata kuliah mekanika tanah. Menurut Asyhar (2012: 81-82), kriteria media pembelajaran yang baik dan perlu diperhatikan dalam proses pemilihan media adalah sebagai berikut: (1) Jelas dan rapi, (2) Bersih dan menarik, (3) Cocok dengan sasaran, (4) Relevan dengan topik yang diajarkan, (5) Sesuai dengan tujuan pembelajaran, (6) Praktis, luwes dan tahan, (7) Berkualitas baik, (8) Ukurannya sesuai dengan lingkungan belajar.

Menurut Gerlack dan Ely dalam Asyhar (2012: 83-84) memberikan lima prinsip. Secara umum, prinsip pemilihan media adalah kesesuaian, kejelasan sajian, kemudahan akses, keterjangkauan, ketersediaan, kualitas, ada alternatif, interaktif, organisasi, kebaruan, dan berorientasi siswa. Jadi untuk membuat media pembelajaran yang baik dan efektif bagi mahasiswa harus memperhatikan kriteria-kriteria media yang baik dan memiliki prinsip. Kriteria yang perlu dipertimbangkan guru atau tenaga pendidik dalam memilih media pembelajaran menurut Sudjana (1990: 4-5) yakni : (1) Ketepatan media dengan tujuan pengajaran, (2) Dukungan terhadap isi bahan pelajaran, (3) Kemudahan memperoleh media, (4) Keterampilan guru dalam menggunakannya, (5) Tersedia waktu untuk menggunakannya, (6) Sesuai dengan taraf berfikir anak.

Secara umum Ariani (2010: 2627) mengemukakan beberapa manfaat multimedia pembelajaran antara lain: (1) Lebih menarik, (2) Lebih interaktif, (3) Jumlah waktu mengajar (ceramah) guru/pendidik dapat dikurangi, (4) Kualitas belajar siswa dapat lebih termotivasi dan terdongkrak, (5) Sikap dan perhatian belajar siswa dapat ditingkatkan dan dipusatkan, (6) Dapat menghidupkan teks dengan menyertakan bunyi, gambar, musik, animasi dan video, (7) Dapat menarik minat karena 
merupakan gabungan antara pandangan, suara dan gerakan.

Manfaat multimedia yang dikemukakan Fenrich (1997) yang dikutip oleh Pramono (Depdiknas 2008) adalah: (1) Siswa dapat belajar sesuai dengan kemampuan, kesiapan dan keinginan mereka, (2) Siswa belajar dari tutor yang sabar (komputer) yang menyesuaikan diri dengan kemampuan dari siswa, (3) Siswa akan terdorong untuk mengejar pengetahuan dan memperoleh umpan balik yang seketika, (4) Siswa menghadapi suatu evaluasi yang obyektif melalui keikutsertaannya dalam latihan/tes yang disediakan, (5) Siswa menikmati privasi (6) Belajar saat kebutuhan muncul ("just-intime” learning), (7) Belajar kapan saja mereka mau tanpa terikat suatu waktu yang telah ditentukan, (8) Mengatasi kelemahan pada pembelajaran kelompok maupun individual.

Kedua pendapat tersebut dapat kita simpulkan bahwa multimedia pembelajaran bisa memotivasi siswa dalam balajar, dan dengan multimedia maka pembelajaran akan berlangsung dengan baik, efektif, dan menyenangkan, karena dapat menarik minat dan perhatian siswa serta dapat meningkatkan hasil belajar siswa.

\section{METODE PENELITIAN}

Metode yang digunakan dalam penelitian adalah metode penelitian dan pengembangan (Research and Development). Adapun penelitian yang akan dikembangkan adalah media pembelajaran berbasis video. Langkah-langkah penelitian mengikuti metode research and development Sugiyono (2014: 409) yang dijelaskan pada gambar 1 sebagai berikut:

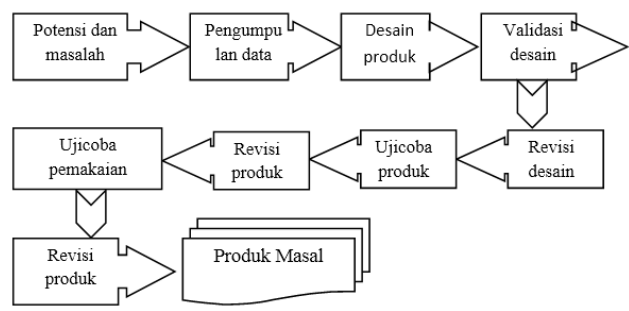

Gambar 1.Tahap-Tahap Penelitian

Research and Development

Rancangan kegiatan penelitian ini hanya sampai pada uji kelayakan media pembelajaran praktek mekanika tanah yang dilanjutkan dengan evaluasi model final. Dengan demikian, tiga langkah penyederhanaan metode penelitian yang dilakukan oleh peneliti yaitu dengan membagi penelitian menjadi tiga bagian, yaitu : tahap studi pendahuluan, tahap pengembangan media, tahap evaluasi yang dijelaskan pada gambar 2 sebagai berikut : 


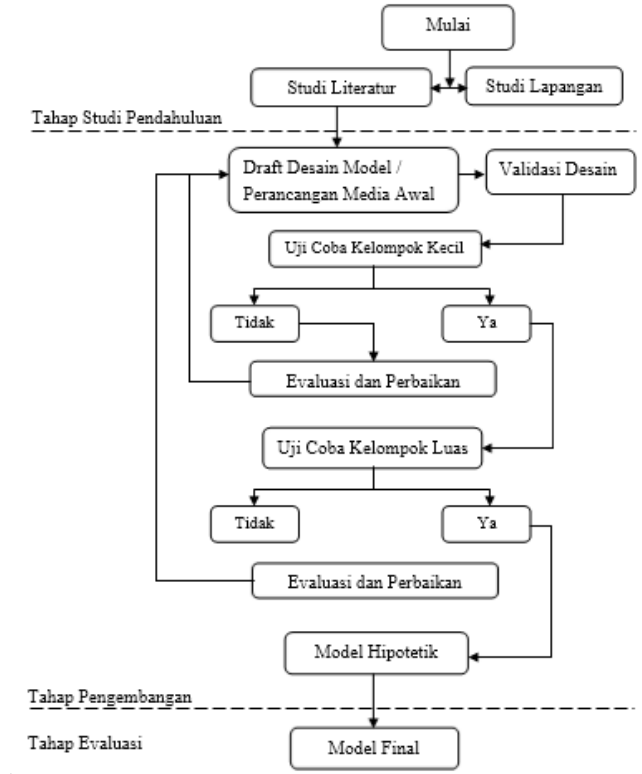

Gambar 2. Alur Prosedur Pengembangan

Instrumen penelitian adalah suatu alat yang digunakan untuk mengukur fenomena alam maupun untuk mengukur fenomena sosial yang diamati.

Penilaian media pembelajaran berbasis video diberikan kepada satu ahli materi, satu ahli media, satu ahli pembelajaran.

Untuk menilai kelayakan media pembelajaran yang telah dibuat, maka dipakai skala pengukuran dengan menggunakan skala likert. Variabel yang akan diukur, dijabarkan menjadi indikator variabel. Kemudian indikator variabel dijadikan sebagai titik tolak untuk menyusun item-item instrumen yang dapat berupa pernyataan atau pertanyaan. Jawaban setiap item instrumen yang menggunakan skala likert mempunyai gradasi dari sangat positif sampai sangat negatif.

Skala likert berdasarkan pendapat Sugiyono (2013: 136) dijelaskan pada tabel 1 dan 2 sebagai berikut :
Tabel 1. Kriteria Penilaian Kelayakan

\begin{tabular}{lc}
\hline Kategori Penilaian & Skor \\
\hline Sangat Layak & 5 \\
Layak & 4 \\
Cukup Layak & 3 \\
Tidak Layak & 2 \\
Sangat Tidak Layak & 1
\end{tabular}

Tabel 2 Interprestasi Kriteria Hasil Penelitian

\begin{tabular}{cl}
\hline Kategori Penelitian & \multicolumn{1}{c}{ Interprestasi } \\
\hline Sangat Layak & $\begin{array}{l}\text { Ahli materi, ahli media dan ahli pembelajaran } \\
\text { menyatakan bahwa media pembelajaran } \\
\text { berbasis video sangat layak digunakan sebagai } \\
\text { media pembelajaran. }\end{array}$ \\
Lhli materi, ahli media dan ahli pembelajaran \\
Menyatakan bahwa media pembelajaran \\
Cukup Layak & $\begin{array}{l}\text { merbasis video layak digunakan sebagai media } \\
\text { pembelajaran. }\end{array}$ \\
& $\begin{array}{l}\text { Ahli materi, ahli media dan ahli pembelajaran } \\
\text { menyatakan bahwa media pembelajaran } \\
\text { berbasis video cukup layak digunakan sebagai } \\
\text { media pembelajaran. }\end{array}$ \\
Tidak Layak & $\begin{array}{l}\text { Ahli materi, ahli media dan ahli pembelajaran } \\
\text { menyatakan bahwa media pembelajaran } \\
\text { berbasis video tidak layak digunakan sebagai } \\
\text { media pembelajaran. }\end{array}$ \\
Sangat Tidak & $\begin{array}{l}\text { Ahli materi, ahli media dan ahli pembelajaran } \\
\text { menyatakan bahwa media pembelajaran } \\
\text { berbasis video sangat tidak layak digunakan } \\
\text { sebagai media pembelajaran. }\end{array}$ \\
\hline &
\end{tabular}

Proses perhitungan persentase dilakukan dengan cara membandingkan frekuensi yang diperoleh dengan frekuensi yang diharapkan. Persentase dihitung dengan menggunakan rumus sebagai berikut:

Persentase $=\underline{\text { Frekuensi yang diperoleh }} \times 100 \%$ Frekuensi yang diharapkan 


\section{HASIL DAN PEMBAHASAN}

Dalam pelaksanaan penelitian dilaksanakan dengan 3 tahap utama yaitu:

\section{Tahap Studi Pendahuluan}

Pada tahap ini terdiri dari 2 bagian antara lain: studi literatur dan studi lapangan. Studi literatur dilakukan dengan mencari referensi maupun pustaka terkait mata kuliah mekanika tanah. Sedangkan studi lapangan adalah melakukan observasi di lapangan dengan menggali informasi, menggali permasalahan dan mengidentifikasi masalah.

2. Tahap Pengembangan

Pada tahap ini terdiri dari 8 bagian diantaranya:

a. Penyusunan draft desain model. Data yang didapat dari survei lapangan dan ditunjang dengan dasar-dasar teori dari hasil studi kepustakaan selanjutnya peneliti menyusun draft desain model media pembelajaran yang terdiri dari 3 tahap, antara lain:

1) Penyusunan draft materi, naskah, dan storyboard video tutorial. Penyusunan draft materi mengacu pada silabus mekanika tanah.

2) Pengambilan video.

Proses pengambilan video dilakukan di Laboratorium PTB FKIP UNS dan Teknik Sipil UNS

3) Editing video

Proses editing video menggunakan perangkat keras berupa $P C$ dan perangkat lunak Pinnacle Studio 16. Pada tahap ini out put yang dihasilkan berupa media tutorial mekanika tanah dalam bentuk $D V D$. Isi $D V D$ terdiri dari 2 macam yaitu opening dan menu utama, lebih lengkap pada gambar 3, 4 dan 5 di bawah ini.

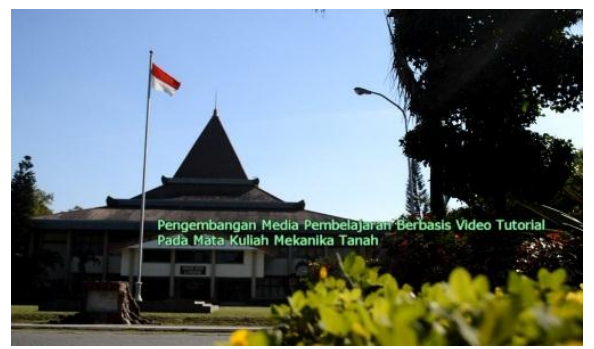

Gambar 3. Opening video

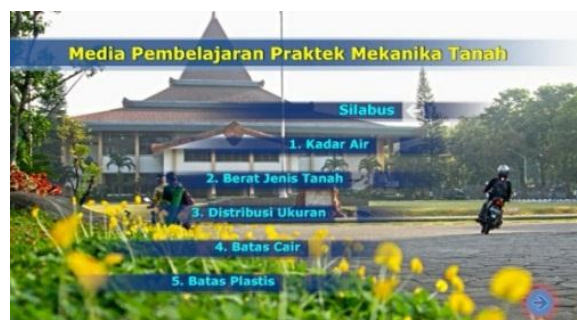

Gambar 4. Menu utama 1

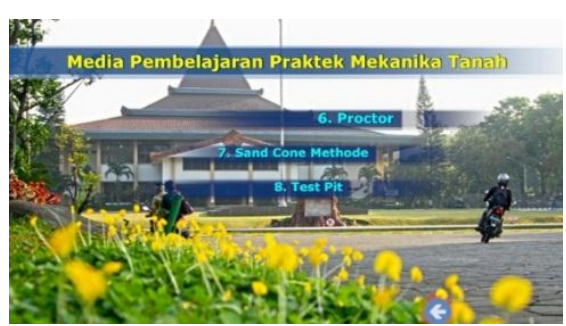

Gambar 5. Menu utama 2

Dalam opening video terdapat judul media pembelajaran yaitu pengembangan media pembelajaran berbasis video tutorial pada mata kuliah mekanika tanah yang telah dikembangkan yang berfungsi untuk mengetahui media interaktif yang dipakai. Sedangkan pada menu utama terdapat 8 materi pembelajaran mekanika tanah, seperti: pengujian kadar air, pengujian proctor, pengujian batas cair, pengujian berat jenis tanah, pengujian 
distribusi ukuran tanah, pengujian batas plastis, pengujian sand cone methode dan pengujian test pit, pengguna dapat memilih materi yang akan dipelajari.

b. Validasi tim ahli (expert judgment)

Validitas penilaian pada penelitian ini mengacu pada pendapat Sugiyono (2013: 168) menyatakan bahwa instrumen yang valid berarti alat ukur yang digunakan untuk mendapatkan data (mengukur) itu valid. Valid berarti instrumen tersebut dapat digunakan untuk mengukur apa yang seharusnya diukur. Penilaian media pembelajaran mekanika tanah dilakukan oleh pakar atau praktisi melalui instrumen penilaian berdasarkan teori-teori yang sudah ada kemudian dijadikan indikator dalam penilaian oleh pakar. Pakar atau praktisi meliputi tiga pakar ahli antara lain : pakar materi, pakar media dan pakar pembelajaran.

Pakar materi yang menilai kelayakan media pembelajaran adalah dosen pengampu mata kuliah mekanika tanah Sri Sumarni. Penyajian data hasil penilaian media pembelajaran oleh ahli materi dijelaskan pada gambar 6 sebagai berikut:

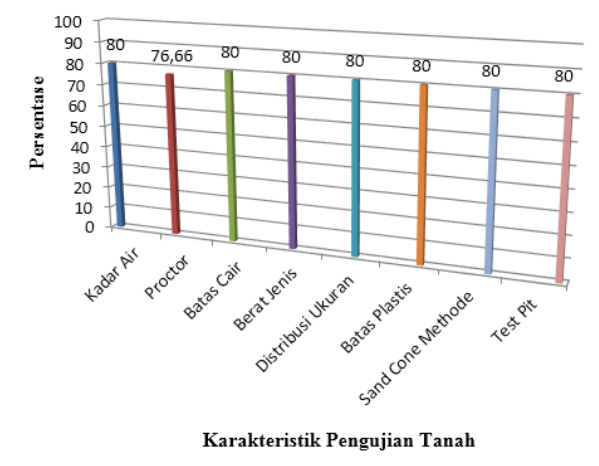

Gambar 6. Diagram penilaian ahli materi

Perhitungan persentase ahli materi yang ditinjau dari relevansi terhadap materi praktek mekanika tanah diantaranya: pengujian kadar air persentase penilaian sebesar $80 \%$, pengujian proctor sebesar $76,66 \%$, pengujian batas cair sebesar $80 \%$, pengujian berat jenis sebesar $80 \%$, pengujian distribusi ukuran butiran sebesar $80 \%$, pengujian batas plastis sebesar $80 \%$, pengujian sand cone method sebesar $80 \%$ dan pengujian test pit sebesar $80 \%$ jika dirata-rata menjadi $79,58 \%$.

Pakar media yang menilai kelayakan media adalah dosen multimedia Pendidikan Teknik dan Informatika FKIP UNS Taufik Lilo Adi Sucipto. Persentase data hasil penilaian ahli media dijelaskan pada gambar 7 sebagai berikut:

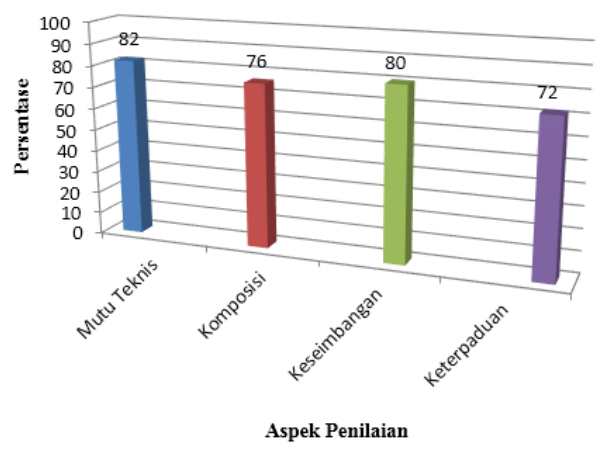

Gambar 7. Diagram penilaian ahli media 
Validasi penilaian oleh ahli media berisi 23 butir pertanyaan dengan indikator antara lain: mutu teknis, komposisi, keseimbangan dan keterpaduan untuk menilai kelayakan media pembelajaran berbasis video tutorial pada mata kuliah mekanika tanah. Dengan persentase penilaian sebagai berikut: aspek mutu teknis sebesar $82 \%$, aspek komposisi sebesar $76 \%$, aspek keseimbangan sebesar $80 \%$, keterpaduan sebesar $72 \%$, jika dirata-rata tingkat kelayakan media pembelajaran berbasis video tutorial menurut penilaian ahli media sebesar $77,5 \%$.

Pakar pembelajaran yang menilai kelayakan media pembelajaran berbasis video tutorial adalah dosen Pendidikan Teknik Bangunan FKIP UNS Abdul Haris Setiawan. Persentase hasil penilaian oleh ahli pembelajaran dijelaskan pada gambar 8 sebagai berikut:

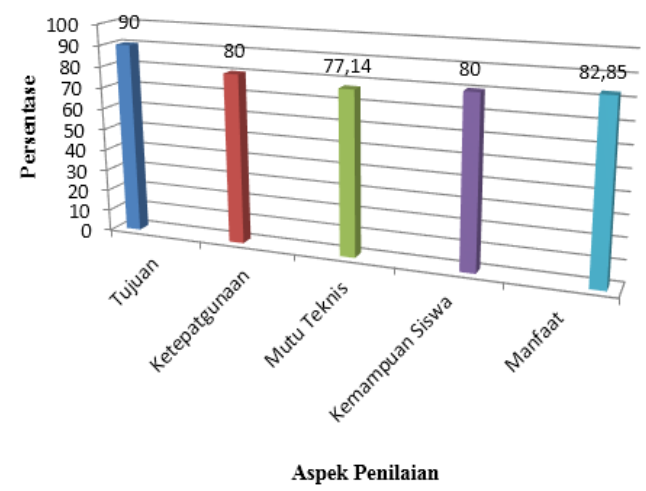

Gambar 8. Diagram penilaian ahli pembelajaran

Penilaian kelayakan oleh ahli pembelajaran melalui validasi penilaian pakar pembelajaran berisi 25 butir pertanyaan. Indikator pertanyaan antara lain: tujuan, ketepatgunaan, mutu teknis, tingkat kemampuan siswa dan manfaat. Dengan persentase hasil penilaian sebagai berikut: aspek tujuan sebesar 90\%, aspek ketepatgunaan sebesar 80\%, aspek mutu teknis sebesar $77,14 \%$, aspek tingkat kemampuan siswa sebesar $80 \%$ dan aspek manfaat sebesar $82,85 \%$. Jika dirata-rata penilaian ahli pembelajaran sebesar $81,99 \%$.

c. Penyusunan penilaian uji coba.

Penilaian uji coba berupa validasi penilaian yang dilakukan oleh pengguna media yaitu mahasiswa. Lembar penilaian disusun berdasarkan indikator-indikator pemilihan media pembelajaran.

Uji coba terbatas dilakukan dengan 3 responden dari mahasiswa kelas A PTB FKIP UNS semester 2 yang mengambil mata kuliah mekanika tanah untuk menilai media pembelajaran yang telah dirancang dan telah melalui validasi dari para ahli. Data penilaian dijelaskan pada gambar 9 sebagai berikut :

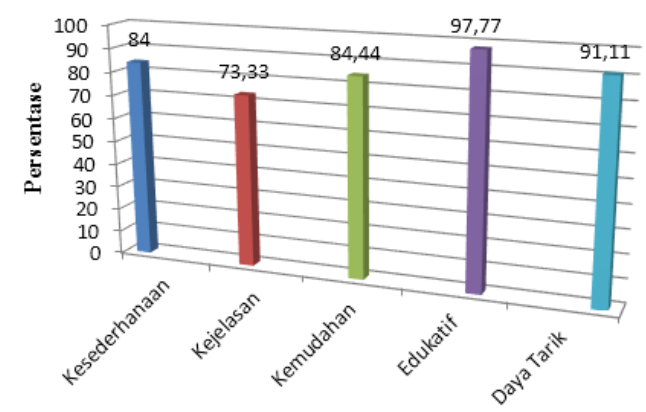

Gambar 9. Diagram penilaian mahasiswa uji coba terbatas

Indikator uji coba terbatas antara lain : kesederhanaan, kejelasan, kemudahan, edukatif, dan daya tarik dengan 23 butir pertanyaan yang diajukan. Persentase hasil penilaian sebagai berikut: aspek kesederhanaan sebesar $84 \%$, aspek kejelasan sebesar $73,33 \%$, aspek kemudahan sebesar 
$84,44 \%$, aspek edukatif sebesar $97,77 \%$ dan aspek daya tarik sebesar 91,11\%. Uji coba terbatas media pembelajaran berbasis video tutorial dirata-rata diperoleh hasil sebesar $86,13 \%$.

Setelah itu media pembelajaran berbasis video tutorial pada mata kuliah mekanika tanah dilakukan uji coba luas di kelas A PTB FKIP UNS diikuti sebanyak 32 mahasiswa. Diperoleh data persentase kelayakan dalam bentuk diagram yangdijelaskan pada gambar 10 sebagai berikut:

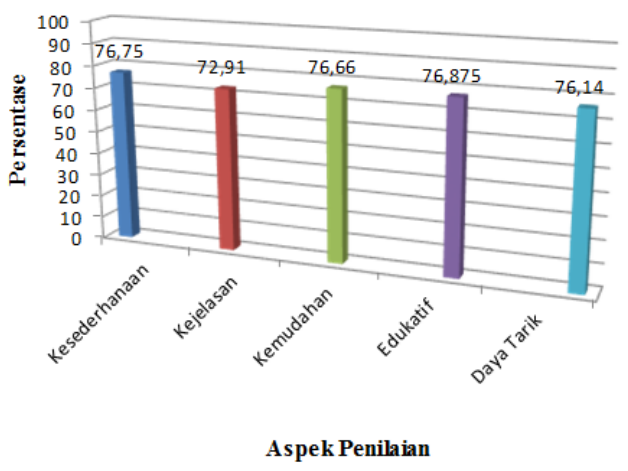

Gambar 10. Diagram penilaian mahasiswa uji coba luas

Berdasarkan indikator berupa kesederhanaan, kejelasan, kemudahan, edukatif, dan daya tarik dengan 23 butir pertanyaan. Dengan persentase penilaian diantaranya: aspek kesederhanaan sebesar $76,75 \%$, aspek kejelasan sebesar 72,91\%, aspek kemudahan sebesar $76,66 \%$, aspek edukatif sebesar $76,875 \%$, aspek daya tarik sebesar 76,14\%. Rata -rata penilaian pada uji coba luas sebesar $75,867 \%$.

Kelayakan media pembelajaran berbasis video tutorial yang ditinjau oleh ahli materi, ahli media, ahli pembelajaran dan mahasiswa selaku pengguna / pemakai media pembelajaran melalui validasi penilaian berupa instrumen, mengacu pendapat Sugiyono (2013: 136), dapat dilihat pada tabel 3 berikut:

Tabel 3 Kelayakan Berdasarkan Instrumen Penilaian

\begin{tabular}{clcc}
\hline No. & \multicolumn{1}{c}{ Penilai } & Hasil (\%) & Kelayakan \\
\hline 1 & Ahli materi 1 (dosen) & $79,58 \%$ & Layak \\
2 & Ahli media 1 (dosen) & $77,5 \%$ & Layak \\
3 & Ahli pembelajaran 1 (dosen) & $81,99 \%$ & Sangat Layak \\
4 & Mahasiswa (uji coba terbatas) & $86,13 \%$ & Sangat Layak \\
5 & Mahasiswa (uji coba luas) & $75,867 \%$ & Layak \\
\hline
\end{tabular}

\section{Tahap Evaluasi}

Model final merupakan bagian dari tahap evaluasi setelah media pembelajaran video tutorial divalidasi penilaian oleh ahli materi, ahli media dan ahli pembelajaran.

Pengembangan media pembelajaran pada mata kuliah mekanika tanah khususnya praktek tidak terlepas dari peran multimedia yang menghasilkan suatu informasi berupa gambar, suara, dan animasi sehingga peran multimedia sangat membantu dalam penyalur informasi.

Menurut Oetomo (2002: 109), secara umum multimedia diartikan sebagai kombinasi teks, gambar, seni grafik, animasi, suara dan video. Aneka media tersebut digabungkan menjadi satu kesatuan kerja yang akan menghasilkan suatu informasi yang tidak hanya dapat dilihat sebagai hasil cetakan, melainkan juga dapat didengar, membentuk simulasi dan animasi yang dapat membangkitkan minat dan memiliki nilai seni grafis yang tinggi dalam penyajiannya. Ariani \& Haryanto (2010: 25) mengemukakan bahwa multimedia terbagi menjadi dua kategori, yaitu : multimedia linier dan multimedia interaktif. 
Multimedia linier adalah suatu multimedia yang tidak dilengkapi dengan alat pengontrol apapun yang dapat dioperasikan oleh pengguna. Multimedia ini berjalan sekuensial (berurutan). Multimedia interaktif adalah suatu multimedia yang dilengkapi dengan alat pengontrol yang dapat dioperasikan oleh pengguna sehingga pengguna dapat memilih apa yang dikehendaki untuk proses selanjutnya.

Pengembangan

media pembelajaran mata kuliah mekanika tanah khususnya praktek mengacu kategori multimedia interaktif, yaitu media pembelajaran yang dilengkapi alat pengontrol yang dapat dikendali oleh pengguna. Pengembangan media praktek mekanika tanah dirancang dengan memadukan gambar, suara, dan animasi yang digabung menjadi satu kesatuan.

\section{SIMPULAN}

Berdasarkan data hasil penelitian dan pembahasan yang telah dijelaskan pada bab sebelumnya dapat ditarik kesimpulan sebagai berikut:

1. Tersusun media pembelajaran interaktif berbasis video tutorial pada mata kuliah mekanika tanah.

2. Kelayakan media pembelajaran berbasis video tutorial diketahui berdasarkan validasi penilaian ahli materi, ahli media, ahli pembelajaran dan mahasiswa.

a. Ahli materi.

Kelayakan

media

pembelajaran berdasarkan pakar ahli materi dengan persentase sebesar 79,58\% termasuk kategori layak.

b. Ahli media.

Kelayakan media pembelajaran pakar ahli media dengan persentase sebesar 77,5 \% termasuk kategori layak.

c. Ahli pembelajaran.

Kelayakan media pembelajaran berdasarkan pakar ahli pembelajaran dengan persentase sebesar $81,99 \%$ termasuk kategori sangat layak.

d. Uji coba kelompok kecil.

Kelayakan media pembelajaran berdasarkan pendapat 3 mahasiswa kelas A PTB FKIP UNS angkatan 2014 yang mengambil mata kuliah mekanika tanah diperoleh persentase sebesar 86,13\% termasuk kategori sangat layak.

e. Uji coba kelompok luas.

Kelayakan media pembelajaran berdasarkan pendapat 32 mahasiswa kelas A PTB FKIP UNS angkatan 2014 diperoleh persentase sebesar $75,867 \%$ termasuk kategori layak.

\section{SARAN}

1. Media yang dikembangkan adalah media pembelajaran interaktif, maka pengguna dituntut aktif dalam mengoperasikannya.

2. Produk hasil penelitian masih ada kekurangan. Ke depan bagi peneliti yang ingin mengembangkan media pembelajaran berbasis video tutorial dengan software Pinnacle Studio bisa memadukan dengan software Adobe Flash Player agar media pembelajaran lebih interaktif. 


\section{DAFTAR PUSTAKA}

Ariani, N. \& Haryanto, D. (2010). Pembelajaran Multimedia di Sekolah. Jakarta: PT. Prestasi Pustakaraya.

Arsyad, A. (2007). Media Pembelajaran. Jakarta: PT Raja Grafindo Persada.

Asyhar, R. (2012). Kreatif Mengembangkan Media Pembelajaran. Jakarta: Referensi.

Djamarah, S.B, dan Aswan Z. (2010). Strategi Belajar Mengajar. Jakarta: Rineka Cipta.

Oetomo, B.S.D. (2002). E-education; Konsep Teknologi dan Aplikasi Internet Pendidikan. Yogyakarta: Andi.

Riyana, C. (2007). Pedoman Pengembangan Media Video. Bandung: Universitas Pendidikan Indonesia.

Sudjana, N. \& Rivai, A. (1991). Media Pengajaran. Bandung: Sinar Baru.

Sugiyono. (2013). "Metode Penelitian Kuantitatif Kualitatif dan R\&D”. Bandung: Alfabeta.

Sugiyono. (2014). "Metode Penelitian Pendidikan Pendekatan Kuantitatif Kualitatif dan R\&D”. Bandung: Alfabeta.

Susilana, R. \& Riyana, C. (2009). Media Pembelajaran : Hakikat, Pengembangan, Pemanfaatan, dan Penilaian. Bandung: CV. Wacana Prima. 